УДК 69

DOI $10.21661 / \mathrm{r}-474865$

\title{
В.Н. Падерин
}

\section{ОСОБЕННОСТИ СМАЗКИ И ОБДУВКИ ПРЕСС-ФОРМ ЛИТЬЯ ПОД ДАВЛЕНИЕМ С ЦЕЛЬЮ ПОВЫШЕНИЯ КАЧЕСТВА ОТЛИВОК С ПОМОЩЬЮ ЭЛЕКТРИЧЕСКИХ КРАСКОПУЛЬТОВ}

Аннотация: в статье рассмотрены особенности смазки и обдувки прессформ литья под давлением с иелью повыщения плотности отливок путем снижения газов от сгорания смазки за счет нанесения ее тонким, равномерным слоем, что также устраняет нарушения поверхностных слоев отливок. Это достигается применением бесшумных электрических краскопультов, имеющих сопло для распыления с тремя положениями для разных факелов.

Ключевые слова: литье под давлением, смазка формообразующих, обдувка, пресс-формы, остатки облоя, плотность, прочность, герметичность, машина для литья.

\section{V.N. Paderin}

\section{FEATURES OF GREASING AND BLOWING OF PRESS-FORMS FOR CASTING UNDER PRESSURE WITH THE PURPOSE OF FOUNDINGS UPGRADING BY ELECTRIC SPRAY GUNS}

Abstract: the features of greasing and blowing of press-forms for casting under pressure with the purpose of foundings upgrading by the decline of gases from greasing combustion due to the application of a thin, uniform layer, which also eliminates violations of the surface layers of castings are represented in the article. This is achieved by the use of noiseless electric spray guns with a nozzle for spraying with three positions for different torches.

Keywords: casting under pressure, greasing of shape-generated, blowing, press-forms, removals of casting material, closeness, durability, impermeability, machine for casting. 
Постановка проблемы. Литье под давлением - это современный малоотходный, широко распространенный, высокопроизводительный способ изготовления отливок позволяющий получать сложные по конструкции и форме различные литые детали с высокой точностью и качественной поверхностью из цветных сплавов.

Смазка пресс-форм и их обдувка сжатым воздухом от остатков мелких кусочков металла, образующегося после изготовления каждой отливки, является обязательной технологической операцией и наносится на формообразующие матрицы, пуансоны и знаки перед изготовлением каждой детали. Смазка является разделительным слоем между отливкой и пресс-формой и предохраняет от «приваривания» расплавленного металла к пресс-форме, что приводит к не качественному поверхностному слою и браку отливок. Кроме того, смазка уменьшает усилие удаления отливки из пресс-формы. Также смазка позволяет уменьшить количество газов попадающих в тело отливки от сгорания её части под действием температуры расплава за счет тонкого равномерного слоя её нанесения, что повышает плотность, прочность и герметичность литых деталей. Без смазки и обдувки пресс-форм сложно изготовить качественную отливку. Поэтому этой операции уделяется особое значение.

Анализ публикаиий $[1 ; 2]$ и практика литья под давлением показывает, что необходимо совершенствовать технологию качественной смазки пресс-форм тонким равномерным слоем и их обдувки от остатков мелких частиц металла после удаления отливок. Эта проблема в производстве решена недостаточно в полном объеме или решается с применением дорогостоящих смазывающих роботов и сложных устройств, что не выгодно особенно для мелких и средних цехов литья под давлением.

В связи с этим цุелью данной статьи являются рекомендации по повышению качества отливок, изготавливаемых литьём под давлением, упрощением технологии смазки и обдувки пресс-форм, использованию отечественных и зарубежных смазочных материалов с низким объемом выделяющихся газов от сгорания 
части смазки и применением простых устройств для нанесения литейной смазки.

Изложение основного материала. Учитывая, что часть смазки при сгорании от температуры расплавленного металла выделяет большое количество газов, снижающих качества отливок является путь нанесение смазки на пресс-формы тонким равномерныл слоем, но достаточным для предохранения отливок от «приваривания» к пресс-форме и образованию дефектов на поверхностных слоях. Кроме того, обязательно необходимо смазывать все поверхности прессформ которые контактируют с расплавленным металлом, особенно в труднодоступных и глубоких местах.

Из практики литья под давлением автор рекомендует применять три технологических режима смазки пресс-форм:

1. Смазка средним факелом распыления для простых по профилю и не глубоких пресс-форм;

2. Смазка большим факелом для пресс-форм средней сложности рельефа поверхности и глубины смазывания;

3. Смазка факелом из «тумана» с повышенным объемом сжатого воздуха для сложных по профилю и глубоких пресс-форм, чтобы она попала на все труднодоступные поверхности, контактирующие с расплавом;

На основании изложенного рассмотрим примеры трёх типов пресс-форм для литья под давлением с учетом сложности их рельефа и глубины смазывания более подробно.

На рис. 1а показана простая пресс-форма, а на рис. 16 средней сложности с отливкой. 


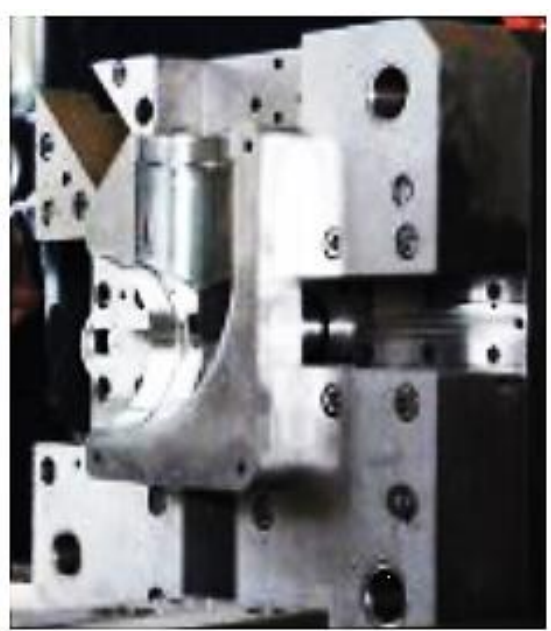

a

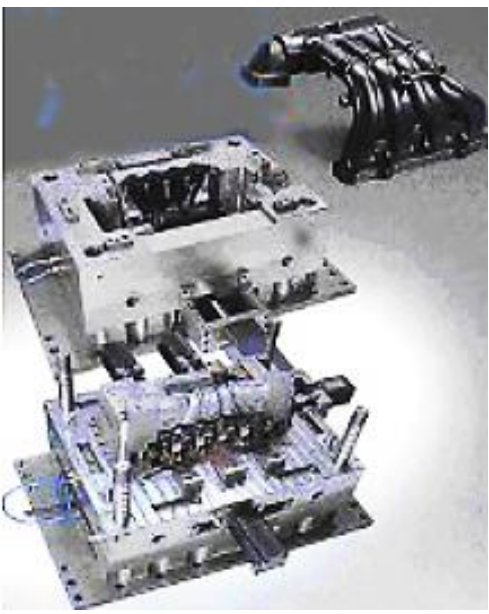

б

Рис. 1. а) простая пресс-форма; б средней сложности с отливкой

Из рис. 1а видно, что такую пресс-форму рекомендуется смазывать средним факелом распыления, а на рис. 16 - большим факелом.

На рис. 2а показана сложная по рельефу и размерам пресс-форма, а на рис. 26 отливка сложной крышки, которые рекомендуется смазывать факелом распыления из «тумана» смазки с большим количеством сжатого воздуха.

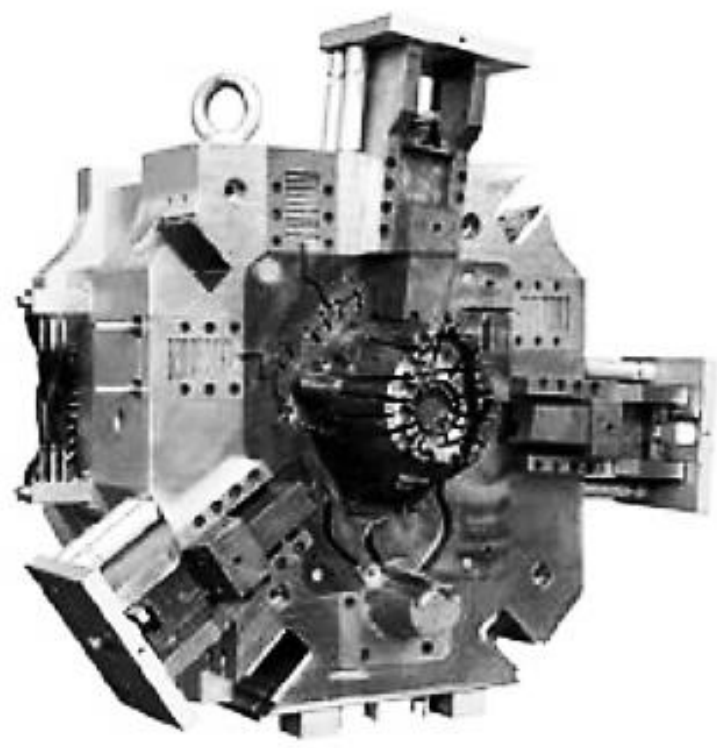

$\mathrm{a}$

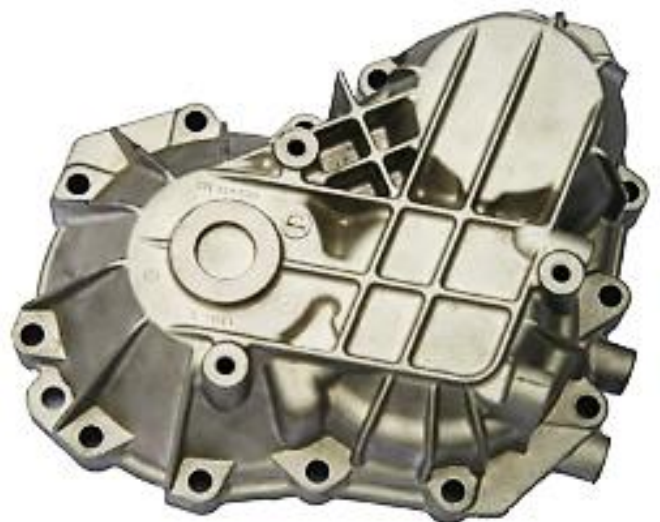

б

Рис. 2. а) сложная по рельефу и размерам пресс-форма;

б отливка сложной крышки

В настоящее время во многих небольших и средних участках и цехах литья под давлением для смазки формообразующих поверхностей пресс-форм всё 
еще применяют смазывание тампонами, щетками и кисточками. Это не позволяет нанести тонкий и равномерный слой смазочного материала на все поверхности, контактирующие с расплавленным металлом, что приводит к дефектам на поверхности отливок и большому количеству газов попадающих в тело отливок от сгорания части смазки из-за высокой температуры расплава, что снижает плотность, прочность и герметичность литых деталей. В результате образуется много брака. Кроме того, при переплавке бракованных отливок выгорает до 6\% металла и увеличиваются затраты на их производство. Поэтому для изготовления высоко качественных отливок смазочный материал должен наносится на пресс-форму только тонким и равномерным слоем с помощью различных простых смазочных устройств, а применение дорогих смазочных роботов экономически не целесообразно.

Учитывая, что современные смазочные материалы для пресс-форм разбавляются водой или различными растворителями до необходимой их вязкости поэтому автором рекомендуется разбавлять литейные смазки до вязкости красок, что позволяет применять современные высоко качественные не дорогие электрические краскопульты имеющие в своей конструкции ресивер нужного объема и турбину для создания сжатого воздуха необходимого давления только те, которые имеют два режима последовательного включения курком. С начало отдельно сжатого воздуха необходимого для обдувки пресс-форм от остатков мелких кусочков металла и затем режима непосредственно для образования необходимого факела для смазки тонким и равномерным слоем. Такая технология опробована и применена автором на ряде предприятий и не требует больших затрат.

На рис. 3 показан наиболее применяемый электрический краскопульт с отдельным ресивером производства Германии модели Bosch PFS55 который рекомендуется применять для ручной обдувки и смазки распылением пресс-форм со средними и большими по площади поверхностями. 


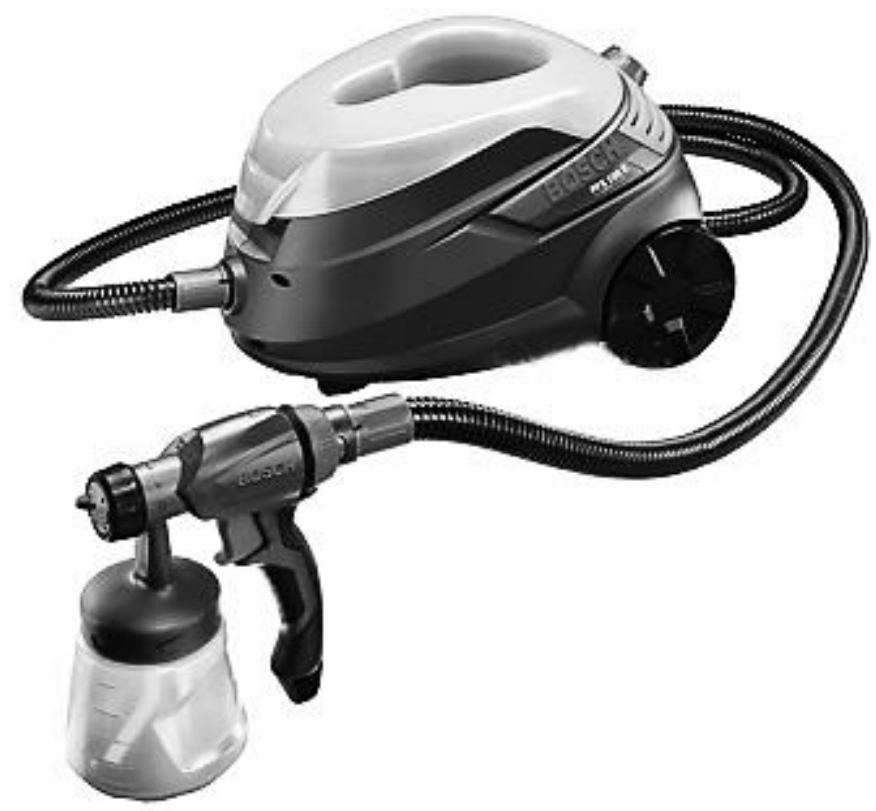

Рис. 3. Электрический краскопульт Bosch PFS55 с рессивером

Краскопульт позволяет работать с разными видами литейных смазок. Точность распыления поддерживается системой BOSCH Spray Control. За счет точности нанесения краскопульт значительно экономит смазку. Кроме того, краскопульт легок для держания в одной руке, поскольку весит всего 1,3 кг.

Преимущества краскопульта Bosch PFS55: 1) Точное нанесение смазки благодаря технологии Spray Control; 2) Система Bosch SDS для быстрой очистки; 3) Встроенная система регулировки расхода смазки; 4) Переносная конструкция; 5) Сопло для распыления смазки с 3 положениями для разных факелов.

Необходимо отметить, что бачка для смазки объемом даже 1 литр хватает практически на смену работы, так как на пресс-форму с весом отливок до 3 кг наносится всего несколько грамм смазочного материала.

Для простых и средних пресс-форм с низким содержанием остатков от мелких частиц металла также рекомендуется применять электрические краскопульты с ресивером для сжатого воздуха установленного прямо над ручкой пульверизатора с электрической турбиной накачивающей воздух встроенной в саму ручку. Это устраняет отдельно стоящий ресивер для сжатого воздуха, снижает вес краскопульта и облегчает работу с ним. 
На рис. 4 показан краскопульт модели WAGNER W450 SE - самый высокопроизводительный и мощный из серии ручных краскопультов имеющий ресивер для сжатого воздуха, установленного над ручкой. Благодаря высоко мощному мотору может распылять как жидкие, так и густые литейные смазки. Его, как правило используют для смазки средних и больших площадей. Краскопульт имеет электронное управление подачи смазки, что позволяет легко управлять процессом смазывания.

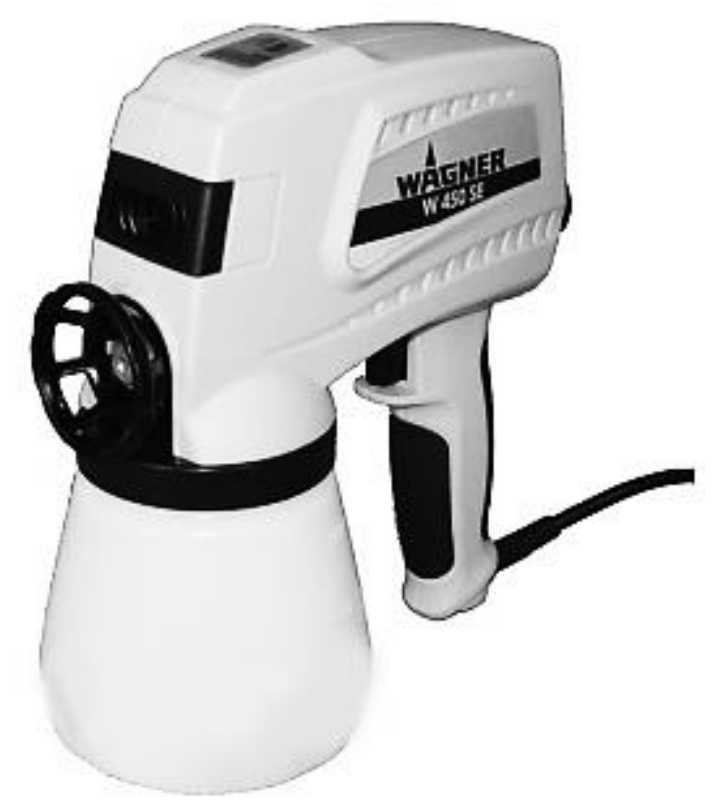

Рис. 4. Электрический краскопульт модели WAGNER W450 SE

Распыление смазки у данного краскопульта осуществляется при помощи поршневой системы (плунжерного типа). Смазка всасывается из бочка при помощи насоса, далее насос под большим давлением подает смазку на сопло (так происходит распыление). Благодаря разборному насосу данный аппарат легко чистится. Также краскопульт WAGNER W450 оснащен электронным управление регулировки подача смазки, что дает возможность смазывать более качественно и точно. Во время распыления смазка ложится равномерно, так как краскопульт WAGNER W450 разбивает её в пыль.

$B$ blвод. Применение электрических краскопультов для смазки и обдувки от остатков металла после литья каждой отливки, воздушных пистолетов, современных смазочных материалов с низкой «газотворной» способностью и пневмоцилиндров для создания сжатого воздуха встроенных в литейную машину 
позволяют повысить качество поверхности и плотность, прочность и герметичность отливок за счет нанесения тонкого и равномерного слоя смазки.

\section{Список литературы}

1. Падерин В.Н. Оборудование современного производства. Литье заготовок и металлообработка в машиностроении: Учебное пособие ГБОУ ВО РК «КИПУ» / В. Н. Падерин. - Симферополь: ДИАЙПИ, 2016. - 253 с.

2. Падерин В.Н. Оборудование современного производства. Ч. 2. Смазка и обдувка пресс-форм литья под давлением и способы снижения газов в отливках: Учебное пособие ГБОУ ВО РК «КИПУ» / В.Н. Падерин, Б.В. Адабашев, Д.У. Абдулгазис. - Симферополь: ДИАЙПИ, 2016. - 189 с.

\section{References}

1. Paderin, V. N. (2016). Oborudovanie sovremennogo proizvodstva. Lit'e zagotovok i metalloobrabotka v mashinostroenii., 253. Simferopol': DIAIPI.

2. Paderin, V. N., Adabashev, B. V., \& Abdulgazis, D. U. (2016). Oborudovanie sovremennogo proizvodstva. Ch. 2. Smazka i obduvka press-form lit'ia pod davleniem i sposoby snizheniia gazov v otlivkakh., 189. Simferopol': DIAIPI.

Падерин Владимир Николаевич - канд. техн. наук, доцент кафедры «Технологическое образование» факультета психологии и педагогического образования ГБОУ ВО РК «Крымский инженерно-педагогический университет», Россия, Симферополь.

Paderin Vladimir Nikolaevich - candidate of technical sciences, associate professor of the Department "Technological education" of the faculty of psychology and pedagogical education of the State budgetary educational institution of higher education of the Crimean Republic "Crimean Engineering and Pedagogical University", Russia, Simferopol. 